\title{
UPPER ENDOSCOPY VERSUS ENDOSONOGRAPHY IN DIFFERENTIAL DIAGNOSIS OF GASTROINTESTINAL BULGING
}

\author{
José Celso ARDENGH ${ }^{1,2}$, Spencer VAICIUNAS ${ }^{1}$, Rafael KEMP¹, \\ Filadelfo VENCO ${ }^{3}$, Éder Rios LIMA-FILHO' ${ }^{1}$ and José Sebastião dos SANTOS ${ }^{1}$
}

\begin{abstract}
Context - The identification of a bulging covered by normal epithelium is a common finding during an upper gastrointestinal endoscopy. Objective - To compare the endoscopic and endosonography findings in the differential diagnosis of the gastrointestinal bulging (subepithelial tumor or extrinsic compression). Method - Patients referred by endosonography with bulging of upper gastrointestinal tract were studied retrospectively. The size, location, consistency and presumptive diagnosis were recorded at time of endoscopy and endosonography. Endosonography-guided fine-needle aspiration was proposed in case of uncertain diagnose to increase diagnostic sensitivity. Results - One hundred seventy-six patients (93 women) and mean age 62.5 years (10-87). One hundred fifty-three had subepithelial tumor and 23 had extrinsic compression as a final diagnosis. Endosonography had sensitivity, specificity and accuracy higher than those found by endoscopy for both diagnosis subepithelial tumor and extrinsic compression. Endoscopy and endosonography showed poor concordance $(\mathrm{K}=0.13)$ for subepithelial tumor diagnosis and unsuitable agreement for diagnosis in extrinsic compression $(\mathrm{K}=0.01)$. The endosonography-guided fine-needle aspiration had sensitivity, specificity, positive predictive value, negative predictive value and accuracy of 75\%,72.4\%, 80.5\%, 65.6\% and 74\%, respectively. Conclusion - Endoscopy has high sensitivity and low specificity for subepithelial tumor and both are low for the extrinsic compression. Endoscopy is a good tool for diagnosis of the subepithelial tumors, but not to determine the cause of an extrinsic compression. The endosonography identifies the layer from which subepithelial tumor comes, obtain histological samples, and increasing the diagnostic accuracy.
\end{abstract}

HEADINGS - Endoscopy, gastrointestinal. Endosonography. Gastrointestinal neoplasms.

\section{INTRODUCTION}

The identification of a lesion covered by normal epithelium is a common finding during an upper gastrointestinal endoscopy (UGE) ${ }^{(15)}$. These lesions are often classified as submucosal, but must be properly named as subepithelial tumors (SET), as they may arise from any layer of the gastrointestinal wall or even outside (extrinsic compression) ${ }^{(13)}$. Therefore, a gastrointestinal bulging may correspond to an extrinsic compression (EC) or an $\mathrm{SET}^{(9,12)}$. The diagnosis of these lesions is sometimes difficult, even after endoscopic biopsy, which usually does not contribute to accurate diagnosis ${ }^{(6,11)}$

Endosonography (EUS) can better locate SET assess echogenicity ${ }^{(7,13,19)}$. Also, in SET, EUS can demonstrate the origin layer into gastrointestinal wall and can obtain tissue with fine-needle aspiration ${ }^{(6,11,12)}$. Any way the presumptive diagnosis by UGE is difficult to be done, especially in $\mathrm{EC}^{(13)}$.
The aim of this study was to compare the performance of UGE vs EUS in the differential diagnosis of upper gastrointestinal bulging and the role of endosonography-guided fine-needle aspiration (EUS-FNA) in the etiology of these lesions.

\section{METHODS}

From January 2002 to January 2007, patients were consecutively referred to EUS evaluation of upper gastrointestinal bulging detected by UGE performed in other medical institutions. All were examined at the Department of Endoscopy and Endoscopic Ultrasound, Hospital 9 de Julho, São Paulo, SP, Brazil. All EUS examinations were performed by the same examiner (JCA), which has over 19 years experience. Patient's age, sex, and symptoms that led to UGE were registered as well the finding of bulging was or not incidental. Patients, whose records could not be examined or whose diagnosis could not be assured by pathology, surgery or follow-up were excluded.

Financial disclosure: the authors have no conflicts of interest or financial ties to disclose.

Divisão de Endoscopia e Ecoendoscopia, Faculdade de Medicina de Ribeirão Preto, Universidade de São Paulo, Ribeirão Preto; ${ }^{2}$ Departamento de Endoscopia e Ecoendoscopia Digestiva, Hospital Nove de Julho, São Paulo; ${ }^{3}$ Departamento de Patologia, Diagnóstika, São Paulo, SP, Brazil.

Correpondence: Dr. José Celso Ardengh - Alameda dos Arapanés, 881 - cj. 111 - Brooklin - 04524-001, São Paulo, Brazil. E-mail: jcelso@uol.com.br 


\section{Technical aspects}

\section{Upper gastrointestinal endoscopy}

Before EUS all patients underwent at least one UGE to confirm presence and location of the bulge by the operator JCA, with a large experience in upper endoscopic procedure. During all UGE, patients had sedation with midazolam and meperidine. Propofol was used whenever necessary. Patients remained at endoscopy unit for at least 2 hours after the procedures. UGE were performed using Olympus endoscopes (Olympus Co. Ltd., Tokyo, Japan) and Pentax (Pentax Optical Co. Ltd., Tokyo, Japan). The size, location, and presumptive diagnosis were registered during UGE before the EUS. During endoscopy, the size of gastrointestinal tract bulging was estimated by measuring the diameter of mass, using a biopsy forceps with opened spoons as reference dimension. The endoscopist was required to give his impression about endoscopic consistency (solid, vascular or cystic), type of lesion/location (intramural or extramural) and the presumptive diagnosis based on endoscopic appearance.

\section{Endosonography-guided fine-needle aspiration}

EUS were performed with sectorial echoendoscopes Olympus (GF-UCT-160 - Olympus Corp., Tokyo, Japan) and Pentax (FG 32-UA, FG 36-UX and FG 38-UX Pentax Precision Instruments Corp., Orangeburg, New York). The first was connected to the power of ultrasound model UC-60 (Suzy - Olympus Corp., Tokyo, Japan) and the other to a Hitachi ultrasound unit (EUB 515A, Mitsubishi, Conshockon, Philadelphia, PA, USA). The parameters observed during EUS were carefully recorded independently by the same operator (JCA). During EUS lesion size was measured by electronic method as well its location, whether intramural or extramural. In case of SET, the layer of origin was also identified and recorded. The echotexture of the SET (anechoic, hypoechoic, isoechoic, or hyperechoic) was also recorded. Then the endoscopist gave his opinion about type of lesion (solid, cystic or vascular) and location (intramural or extramural). Then, he made a presumptive diagnosis based on EUS results.

In case of hypoechoic solid lesions, originated in the $3 \mathrm{rd}$ or 4th layers diagnosis was obtained by EUS-FNA, endoscopic resection or surgical specimen. On suspicion of vascular lesion Doppler was used to confirm the suspected diagnosis during EUS. EUS-FNA was proposed in case of uncertain diagnose during EUS to increase diagnostic sensitivity of SET. Tissue specimens were obtained with EUS-FNA or after total excision of the lesion during the EUS. The GIP $22 \mathrm{G}$ needle system was always used for FNA (Medizintechnik GmbH, Grassau, Germany).

\section{Histological evaluation}

All cytological samples were interpreted by one experienced pathologists (FV). Smears were prepared and stained by standard protocol. Once aspirated, the specimens were sent to the cell block technique. The material inside the needle had injected with a $2 \mathrm{~mL}$ syringe filled with sterile saline $10 \%$. All contents inside the needle were included in neutral buffered formalin solution $10 \%$. Shortly after, mandrill was passed through the needle so that residual content was collected. The resulting sample is centrifuged for $5 \mathrm{~min}$ at $2000 \mathrm{rpm}$. Supernatant was discarded and the remaining cells transferred to an Eppendorf tube of 1.5 $\mathrm{mL}$, and then suspended in $1 \mathrm{~mL}$ of a $2 \%$ agarose as means of inclusion. Test-tube is again centrifuged for $1 \mathrm{~min}$ at $1000 \mathrm{rpm}$ to concentrate the cells in agar. Once solidified, the agar cone containing the cells in the upper layer was removed from the test-tube, wrapped in a filter paper, and embedded in paraffin. At this point, the sample could be treated routinely as a block of tissue. The paraffin blocks was then cut into slices of $3 \mathrm{~mm}$ thickness, placed on glass slides and stained with hematoxylin-eosin ${ }^{(2)}$.

\section{Statistical analysis and ethics}

UGE and EUS estimated quality in relation to histology was performed by means of sensitivity, specificity, positive predictive value, negative predictive value and accuracy. A comparison of UGE and EUS results was calculated by Fisher's exact test, given to test the hypothesis Ho that the tests were independent (no association). If the value of $P$ was greater than 0.05 , Ho was not rejected, if less Ho was rejected. The analysis of correlation between UGE and EUS for presumptive diagnosis of extrinsic compression or subepithelial lesions was made by calculating kappa coefficient. All tests were performed using InsStat (GraphPad) program, version of Windows and the level of error type was 0.05 . This study was approved by the Ethics Committee of the University of São Paulo, Ribeirão Preto, SP, Brazil.

In accordance with the requirements specified by the resolution 196/96 of the National Health Council and National Committee for Ethics in Research (CONEP), the project was examined and approved by the Research Ethics (process number 9012/2007). A written informed consent was obtained from each patient. The study protocol complies with the ethical guidelines of the World Medical Association Declaration of Helsinki-Ethical Principles for Medical Research Involving Human Subjects.

\section{RESULTS}

\section{Characteristics of the population studied}

One hundred ninety-eight patients were referred for EUS presenting an upper GI bulging. We excluded 22 patients because histological and/or medical records without the data needed for research were not possible to obtain. We selected 176 patients (93 women) with a mean age of 62.5 years (range 10-87 years).

Epigastric pain led most patients to UGE. The incidental finding of bulging, without symptoms, occurred in 112 patients $(64 \%)$, while $64(36 \%)$ had some type of symptoms or signs related to the bulging: abdominal pain (15\%), gastrointestinal bleeding (11\%), dysphagia (7\%), jaundice $(2 \%)$, and peptic ulcer $(1 \%)$. 
The final diagnosis was SET in $153(87 \%)$ and $23(13 \%)$ patients had EC. Overall the bulging found by UGE and confirmed by EUS was in stomach in $111(63 \%)$, esophagus in $51(29 \%)$ and duodenum $14(8 \%)$. According to location in esophagus or stomach (proximal, middle or distal), bulging found during an UGE, were in the distal third in $36(70 \%)$ and middle in $15(30 \%)$, middle third in $55(50 \%)$, proximal $48(43 \%)$ and distal $8(7 \%)$, respectively. Among 14 patients with duodenal bulging, $9(64 \%)$ were in the first portion and $5(36 \%)$ in the second. The final diagnosis was obtained by surgery (97), endoscopic treatment (32) and follow-up (47).

\section{Evaluation of 153 patients with subepithelial tumors}

In this group, the lesions found were represented by the following structures: 94 gastrointestinal stromal tumors (GIST), 22 leiomyomas, 15 granular cell tumors, 8 lipomas, 6 duplication cysts (duodenal (3) and gastric (3)), 2 duodenal papilla bulging, 2 duodenal polyps, 2 patients with gastric fundus varices and 2 with suspected SETs in UGE not assured by EUS. In this group the final diagnosis was obtained by surgery (93), after endoscopic treatment endorsed by EUS (32) and (28) with a mean follow-up of 22.8 months (8-42 months).

The UGE made the diagnosis of SET in 131 cases. In 66 patients it made a correct presumptive diagnosis for SET: 45 GISTs, 10 leiomyomas, 8 granular cell tumors, 3 lipomas, confirmed by EUS. In 22 patients the UGE reported a bulging, but was confused to say precisely whether it was SET or not. In these cases, EUS showed 6 duplication cysts, 4 GISTs, 3 granular cell tumor, 2 gastric fundus varices, 2 duodenal polyps, 2 papilla bulging (stone (1) and adenoma (1)), 2 normal exams, and 1 lipoma. The sensitivity, specificity, positive and negative predictive value and accuracy of UGE to determine if the lesion was SET compared to the results of EUS were $87 \%, 50 \%, 99 \%, 5 \%$ and $86 \%$, respectively. Statistical analysis showed no significant difference between the UGE and EUS to $\operatorname{SET}(P=0.25)$.

On the other hand the images obtained by EUS accurately detected the presence of SET in 150 patients, 93 gastrointestinal stromal tumors (GIST), 22 leiomyomas, 15 granular cell tumors, 8 lipomas, 6 duplication cysts (duodenal (3) and gastric (3)), 2 duodenal papilla bulging, 2 duodenal polyps, and 2 patients with gastric fundus varices. It failed to detect a case with extrinsic duodenal GIST (1) misinterpreted like a neuroendocrine tumor of the pancreas. Another two cases related as bulging by UGE was normal by EUS (true negative). The results of EUS for the diagnosis of SET were: sensitivity $99 \%$, specificity $100 \%$, positive predictive value (PPV) 100\%, negative predictive value (NPV) 66\% and accuracy $99 \%(P=0.0003)$.

\section{Endoscopic management}

Table 1 shows the management of 32 patients suspected to have bulging of the upper gastrointestinal tract. There were no complications during or after treatment. All resected tumors were smaller than $2.0 \mathrm{~cm}$ (Figures $1 \mathrm{a}, 1 \mathrm{~b}$ and $1 \mathrm{c}$ ). Estimate quality of UGE for evaluation of SET showed
TABLE 1. Type of endoscopic treatment in 32 patients suspected to have SET by UGE

\begin{tabular}{|c|c|c|}
\hline Treatment & $\mathrm{n}$ & Type of injury treated (n) \\
\hline Endoscopic resection & 24 & $\begin{array}{l}\text { GIST (10), Abrikossof (99), leiomyoma } \\
\text { (3), lipoma (2) }\end{array}$ \\
\hline Endoscopic drainage & 4 & Cysts (duodenal (2), gastric (2)) \\
\hline Polipectomy & 2 & Carcinoid tumor \\
\hline Sphincterotomy & 1 & Impacted stone in duodenal papilla (1) \\
\hline Papillectomy & 1 & Adenoma of papilla (1) \\
\hline
\end{tabular}

SET = subepithelial tumors; UGE = upper gastrointestinal endoscopy

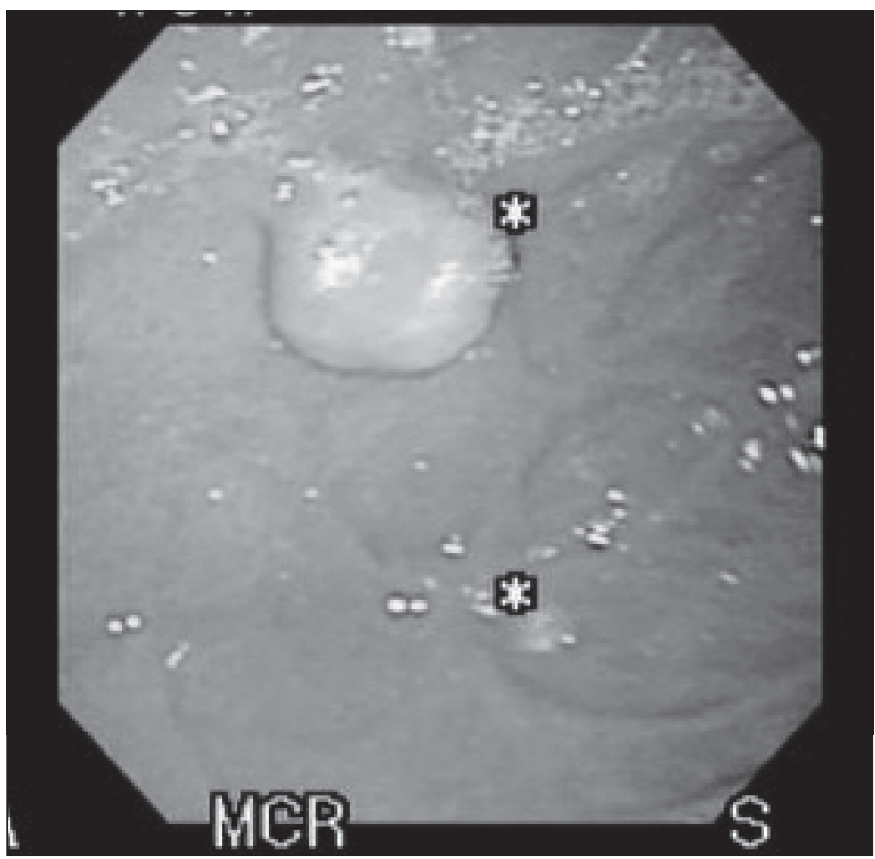

FIGURE 1A. Endoscopic appearance of SET (GIST) located in anterior gastric wall

SET - subepithelial tumors; GIST - gastrointestinal stromal tumors

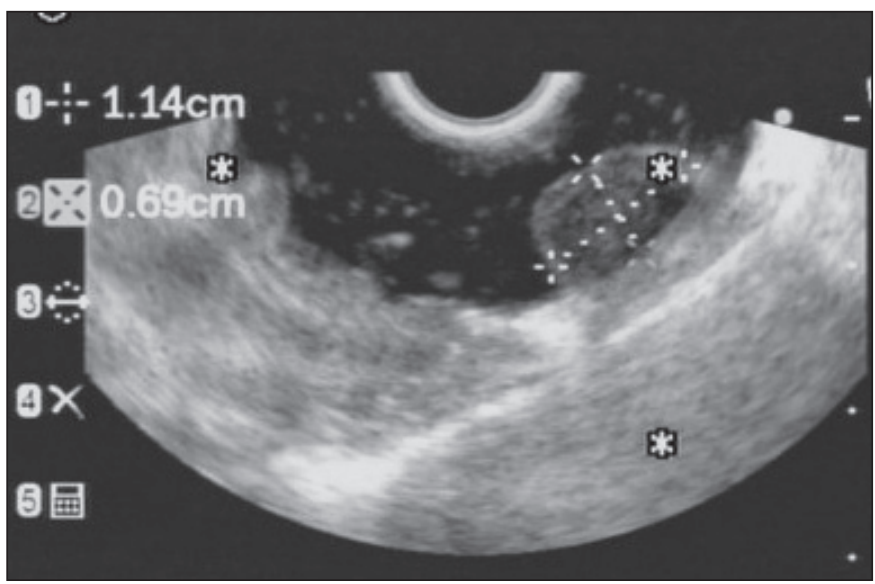

FIGURE 1B. EUS show a lesion of the second layer EUS - endosonography 


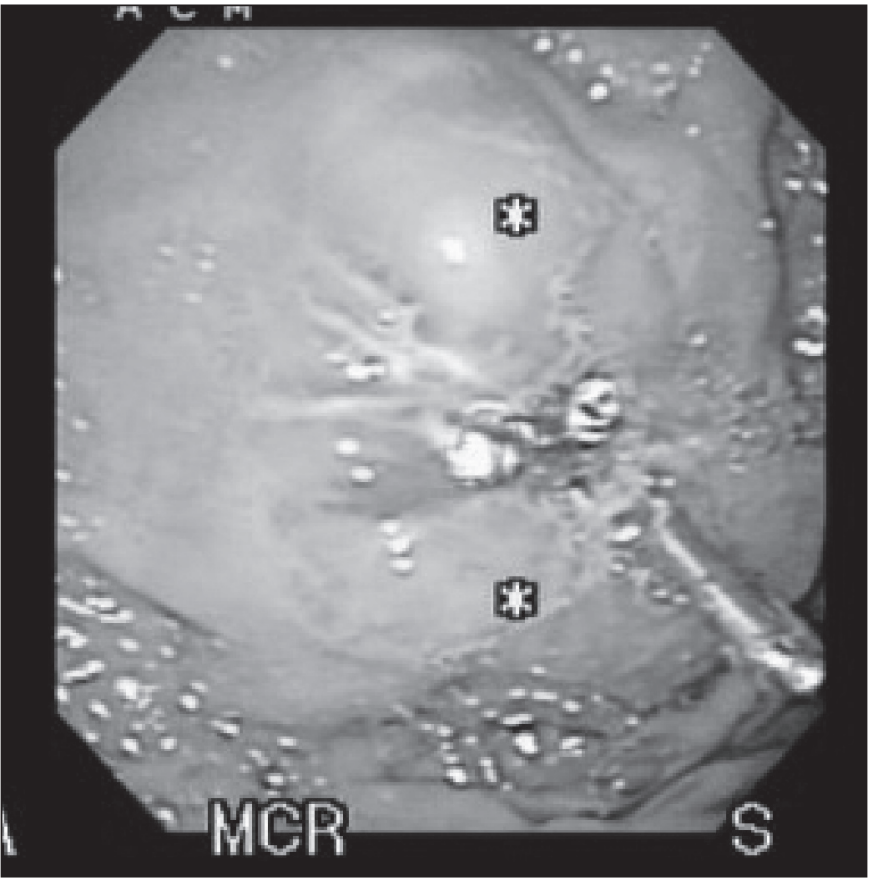

FIGURE 1C. After excision of the lesion

sensitivity, specificity, positive predictive value, negative and accuracy of $86.7 \%, 50 \%, 99.2 \%, 50 \%$ and $86.3 \%$, respectively $(P=0.25)$. Statistical analysis for diagnosis of SET showed no association between diagnosis and UGE. The EUS-FNA had a sensitivity, specificity, positive predictive value, negative and accuracy of $99.3 \%, 100 \%, 100 \%, 66.7 \%$ and $99.3 \%$, respectively $(P=0.0003)$. Statistical analysis showed a strong correlation between EUS-FNA and the correct diagnosis of SETs.

\section{Evaluation of 23 patients with extrinsic compression}

The 23 patients with EC that mimicking SET had the follow diagnosis: compression by the liver edge (7), spleen (5), pancreatic cysts (5), gallbladder (4), bronchogenic cyst (1) and in one of these it was not possible to determine the cause of bulging described by UGE, because EUS was normal. Final diagnosis was obtained by EUS in 19 cases, and surgery in 4: gallbladder with stone (1), serous cystadenoma (1), mucinous cystadenoma (1), and bronchogenic cyst (1). The UGE made the diagnosis of EC in 24 cases. In 9 patients it made a correct presumptive diagnosis for EC: liver (3), spleen (2), pseudocyst (2) and gallbladder (2), confirmed by EUS. In 13 patients the UGE reported a bulging, but was confused to say precisely whether it was EC or not. In these cases, EUS showed that it was EC by the liver (4), spleen (3), serous cystadenoma (1), pseudocyst (1), mucinous cystadenoma (1), gallbladder with stones (1), normal gallbladder (1) and a bronchogenic cyst that EUS imagined as a SET of the middle third of the esophagus (1). In other case UGE presumed diagnosis of EC, but in fact it was gastric varices and other one described as a bulging by UGE was not assured. The sensitivity, specificity, positive and negative predictive value PPV/NPV and accuracy of UGE to determine if the lesion was EC compared to the results of EUS were $40.9 \%, 50 \%, 90 \%, 7.1 \%$ and $41.7 \%$, respectively. Statistical analysis showed no significant difference between the UGE and EUS to EC $(P=0.43)$.

On the other hand the images obtained by EUS accurately detected the presence of EC in 21 patients, liver (7), spleen (5), pancreatic cysts (5) and gallbladder (4). It failed to detect an esophageal bronchogenic cyst compressing the wall of the esophagus, and the result of EUS was esophageal duplication cyst and surgery revealed a bronchogenic cyst compressing the wall of the esophagus. Another one related as bulging by UGE was normal by EUS (true negative). The results of EUS for the diagnosis of EC were: sensitivity $95 \%$, specificity $100 \%$, PPV $100 \%$, NPV $50 \%$ and accuracy $95.7 \%(P=0.08)$.

\section{Concordance between UGE and EUS}

Concordance between UGE and EUS findings was also assessed by kappa. The results of the UGE and EUS had kappa coefficient agreement unsuitable for obtaining a diagnosis of $\mathrm{EC}(\mathrm{k}=-0.01)$ and poor concordance $(\mathrm{k}=0.13)$ for diagnosis in SET of the esophagus, stomach and duodenum.

\section{Results of endosonography-guided fine-needle aspiration}

The EUS-FNA was performed in 73/176 (64.2\%) patients. The sensitivity, specificity, PPV, (NPV and accuracy were $75 \%$, $72.4 \%, 80.5 \%, 65.6 \%$ and $74 \%$, respectively for diagnosis of 44 gastrointestinal stromal tumors (malignant) and other lesions such as leiomyomas (16), pancreatic cystic lesions (5), granular cells tumor (3), gastric duplication cyst (3), duodenal duplication cyst (1) and lipoma (1).

\section{DISCUSSION}

Several studies determined the usefulness of images obtained by EUS for evaluation of SET ${ }^{(3,4,12,14,16)}$. However, a study conducted at a single tertiary care center, comparing the endoscopy and endosonography for evaluating patients with bulging gastrointestinal tract lesions has not been so far reported. There is a multicenter study comparing UGE and images obtained by EUS to differentiate extrinsic compression by subepithelial tumor, but without using FNA to improve the diagnosis ${ }^{(17)}$.

In this retrospective study the authors compare the UGE and the images of EUS for evaluation of 23 patients with EC and 153 with SET, a total of 176 consecutive patients. The objectives were: determine whether UGE identifies and distinguishes accurately an SET versus EC; if EUS is superior to the UGE to determine the location of a bulging of upper gastrointestinal tract (intramural or extrinsic); if the image obtained by EUS improves accuracy in the diagnosis of SET and the EUS-FNA increases the diagnostic accuracy. It seems that our goals have been achieved! 
So far there are no studies comparing the presumptive visual diagnosis of an upper gastrointestinal bulging obtained by UGE, EUS-FNA or surgical specimen. Our results suggest that UGE may be sufficient to characterize and/or diagnose some SET based on certain endoscopic criteria (e.g., color, consistency, mobility, tent signal). UGE has particularly a high specificity in diagnosis of SET based on presence or absence of pillow sign $(90 \%)$, although the sensitivity of tent signal tends to be low $(40 \%)^{(10)}$.

These results were quite different from those found in our study, since the specificity and sensitivity for diagnosis of SET with UGE were $50 \%$. We should emphasize that even in the previous study these results were limited by small number of lesions with tent sign and the small number of lipomas diagnosed in our study by EUS reached 8/176 (4.5\%). Moreover, UGE was not helpful to accurately determine the type of SET, so our results confirm the need for EUS to evaluate such SET.

Previous studies have shown that even when the endoscopist suspected an SET, mass can be found outside the wall of gastrointestinal tract up to $30 \%$ of cases $^{(10,12)}$. An international multicenter study showed that sensitivity and specificity to properly differentiate SET from EC by UGE alone was $87 \%$ and $29 \%$, respectively ${ }^{(17)}$. In another study in $15 \%$ of cases with initial suspicion for SET mass the final diagnosis was $\mathrm{EC}^{(10)}$. The same occurred in our study; $16 \%$ of patients referred for EUS as a subepithelial tumor by UGE had a final diagnosis of EC. The results of this same study show that UGE has a sensitivity of $98 \%$ and specificity of $64 \%$ to determine whether an $\mathrm{SET}^{(10)}$. In our study using the same criteria, the sensitivity of UGE was $87 \%$ and specificity $50 \%$.

In turn, EUS provide us valuable additional information about the layer where SET comes from, which cannot be determined on the basis of a simple endoscopic examination ${ }^{(9)}$. Moreover, EUS is usually able to identify the origin of an $\mathrm{EC}^{(8,10,12)}$. This occurred with greater sensitivity and accuracy for EUS (95\% and 95.7\%) compared to UGE ( $40.9 \%$ and $41.7 \%$ ). The variability between the two methods (EUS vs UGE) was minimal, using similar criteria for assessing lesion size, location and agreement with UGE comparing to EUS. Using images by EUS endoscopist has improved so much the performance for presumptive diagnosis of bulging and such diagnosis can be even improved if material for pathological examination is possible to be obtained.

Unlike other study increased confidence can be justified, as there is agreement between presumptive diagnosis by EUS and histological diagnosis 54/73 (74\%) where the tissue was sampled $(44 \%)^{(9)}$. However, it is important to note that the decision to obtain tissue was sometimes performed due to uncertainty about diagnosis (GIST vs leiomyoma), large tumors of esophagus, cystic lesion or lesions in the fourth layer with up two criteria of malignancy ${ }^{(14)}$.

In this study there were no difficulties for obtaining material from benign lesions (leiomyomas, pancreatic cysts, among others), to assess the accuracy of EUS-FNA. Seems obvious that is not justified to obtain biopsy material in clearly benign lipomas. Previous studies have reported the results to determine the malignant or benign potential of a SET by EUS ${ }^{(14,17)}$. The location, echotexture, size and margins of the lesion can be used to assess the risk of malignancy. If a lesion, based on EUS criteria, seems to carry a low malignant potential, tissue samples must be obtained. However, a previous study showing that the image of a SET measured only by EUS without obtaining tissue samples is insufficient to establish the correct histological diagnosis in some conditions $\mathrm{s}^{(1,5,10)}$. In our study, presumptive diagnosis of EUS was failed in 19 of 73 cases $(26 \%)$ when histology was available. The misdiagnosis occurred in hypoechoic, irregular and heterogeneous lesions originating in third or fourth layers by EUS (corresponding to submucosal and muscularis propria, respectively).

Therefore, for hypoechoic lesions in 3rd and 4th layers, histological confirmation, by endoscopic submucosal resection or EUS-FNA should be obtained whenever possible ${ }^{(18)}$. The results of this study suggest that EUS has high sensitivity $(95 \%)$, specificity $(100 \%)$ and accuracy $(95.7 \%)$ compared to UGE with $40.9 \%, 50 \%$ and $41.7 \%$, respectively, to identify if a bulging of upper-GI is caused by EC. However, if the bulge is caused by a SET our results suggest that endoscopy has a sensitivity of $86.8 \%$, specificity of $50 \%$ and accuracy of $86.3 \%$, while EUS has a sensitivity of $99.3 \%$, specificity of $100 \%$ and accuracy of $99.3 \%$, showing an excellent performance. In addition, EUS makes possible precise identification of the layer where the lesion is, distinguishing intrinsic and extrinsic bulging (accurately identifies the source) and obtain histological samples, which cannot be obtained through the UGE, thus raising the diagnostic performance of this method.

UGE has high sensitivity and low specificity to identify SET. In EC it has low sensitivity, specificity and accuracy rates. So it is unsuitable to differentiate EC from SET, but it is a good test to confirm the diagnosis of SET. On the other hand, EUS-FNA has high sensitivity, specificity and accuracy in all types of SET, enabling accurate diagnosis of the layer containing the lesion, which allows distinguishing them and obtaining histological samples, considerably increasing their diagnostic performance. 
Ardengh JC, Vaiciunas S, Kemp R, Venco F, Lima-Filho ER, Santos JS. Endoscopia digestiva alta versus ecoendoscopia no diagnóstico diferencial dos abaulamentos gastrointestinais. Arq Gastroenterol. 2011;48(4):236-41.

RESUMO - Contexto - Abaulamentos da parede do trato gastrointestinal cobertos por epitélio normal são achados comuns durante endoscopia digestiva alta. Objetivos - Comparar os achados da endoscopia com os da ecoendoscopia no diagnóstico diferencial entre tumor subepitelial e compressão extrínseca. Método - Estudaram-se, retrospectivamente, pacientes com abaulamento do trato gastrointestinal alto encaminhado à ecoendoscopia. O tamanho, localização, consistência e o diagnóstico presuntivo foram registrados no momento da endoscopia e da ecoendoscopia. Esta associada à punção aspirativa com agulha fina foi proposta nos casos de dúvida para aumentar a sensibilidade diagnóstica. Resultados - Cento e setenta e seis pacientes (93 mulheres), com média de idade de 62,5 anos (10-87 anos). O diagnóstico final foi de tumor subepitelial em 153 (87\%) e compressão extrínseca em 23 (13\%). A sensibilidade, especificidade e precisão obtida pela ecoendoscopia foram superiores as da endoscopia, tanto para o diagnóstico do tumor subepitelial como de uma compressão extrínseca. A endoscopia e a ecoendoscopia mostraram concordância ruim $(\mathrm{k}=0,13)$ para o diagnóstico de tumor subepitelial e concordância inadequada para o diagnóstico de compressão extrínseca $(\mathrm{k}=0,01)$. A punção aspirativa com agulha fina apresentou sensibilidade, especificidade, valor preditivo positivo, valor preditivo negativo e precisão de $75 \%, 72,4 \%, 80,5 \%, 65,6 \%$ e 74\%, respectivamente. Conclusão - A endoscopia tem alta sensibilidade e baixa especificidade para o diagnóstico de tumor subepitelial. No caso de compressão extrínseca a sensibilidade e especificidade são baixas. A ecoendoscopia identifica a camada de origem do tumor subepitelial, obtém amostras histológicas e aumenta a precisão diagnóstica.

DESCRITORES - Endoscopia gastrointestinal. Endossonografia. Neoplasias gastrointestinais.

\section{REFERENCES}

1. Akahoshi K, Sumida Y, Matsui N, Oya M, Akinaga R, Kubokawa M, Motomura Y, Honda K, Watanabe M, Nagaie T. Preoperative diagnosis of gastrointestinal stromal tumor by endoscopic ultrasound-guided fine needle aspiration. World $\mathrm{J}$ Gastroenterol. 2007;13:2077-82.

2. Ardengh JC, Lopes CV, de Lima LF, Venco F, Santo GC, Begnami MD, Módena JL. Cell block technique and cytological smears for the differential diagnosis of pancreatic neoplasms after endosonography-guided fine-needle aspiration. Acta Gastroenterol Latinoam. 2008;38:246-51.

3. Boyce GA, Sivak MV Jr, Rösch T, Classen M, Fleischer DE, Boyce HW Jr, Lightdale CJ, Botet JF, Hawes RH, Lehman GA. Evaluation of submucosal upper gastrointestinal tract lesions by endoscopic ultrasound. Gastrointest Endosc. 1991;37:449-54.

4. Buscarini E, Stasi MD, Rossi S, Silva M, Giangregorio F, Adriano Z, Buscarini L. Endosonographic diagnosis of submucosal upper gastrointestinal tract lesions and large fold gastropathies by catheter ultrasound probe. Gastrointest Endosc. 1999;49:184-91.

5. Cantor MJ, Davila RE, Faigel DO. Yield of tissue sampling for subepithelial lesions evaluated by EUS: a comparison between forceps biopsies and endoscopic submucosal resection. Gastrointest Endosc. 2006;64:29-34.

6. Chak A. EUS in submucosal tumors. Gastrointest Endosc. 2002;56:s43-8.

7. Eckardt AJ, Wassef W. Diagnosis of subepithelial tumors in the GI tract. Endoscopy, EUS, and histology: bronze, silver, and gold standard? Gastrointest Endosc. 2005;62:209-12.

8. Hwang JC, Kim JH, Kim JH, Shin SJ, Cheong JY, Lee KM, Yoo BM, Lee KJ, Cho SW. Endoscopic resection for the treatment of gastric subepithelial tumors originated from the muscularis propria layer. Hepatogastroenterology. 2009;56:1281-6.

9. Hwang JH, Kimmey MB. The incidental upper gastrointestinal subepithelial mass. Gastroenterology. 2004;126:301-7.
10. Hwang JH, Saunders MD, Rulyak SJ, Shaw S, Nietsch H, Kimmey MB. A prospective study comparing endoscopy and EUS in the evaluation of GI subepithelial masses. Gastrointest Endosc. 2005;62:202-8.

11. Mallery S. EUS for the evaluation of subepithelial tumors and thickened gastric folds. Rev Gastroenterol Mex. 2003;68(suppl 3):68-73.

12. Motoo Y, Okai T, Ohta H, Satomura Y, Watanabe H, Yamakawa O, Yamaguchi Y, Mouri I, Sawabu N. Endoscopic ultrasonography in the diagnosis of extraluminal compressions mimicking gastric submucosal tumors. Endoscopy. 1994;26:239-42.

13. Nickl N. Endoscopic approach to gastrointestinal stromal tumors. Gastrointest Endosc Clin N Am. 2005;15:455-66, viii.

14. Palazzo L, Landi B, Cellier C, Cuillerier E, Roseau G, Barbier JP. Endosonographic features predictive of benign and malignant gastrointestinal stromal cell tumours. Gut. 2000;46:88-92.

15. Polkowski M, Butruk E. Submucosal lesions. Gastrointest Endosc Clin N Am 2005; 15:33-54, viii.

16. Rösch T, Lorenz R, Dancygier H, von Wickert A, Classen M. Endosonographic diagnosis of submucosal upper gastrointestinal tract tumors. Scand J Gastroenterol. 1992;27:1-8.

17. Rösch T, Kapfer B, Will U, Baronius W, Strobel M, Lorenz R, Ulm K. Accuracy of endoscopic ultrasonography in upper gastrointestinal submucosal lesions: a prospective multicenter study. Scand J Gastroenterol. 2002;37:856-62.

18. Sepe PS, Moparty B, Pitman MB, Saltzman JR, Brugge WR. EUS-guided FNA for the diagnosis of GI stromal cell tumors: sensitivity and cytologic yield. Gastrointest Endosc. 2009;70:254-61.

19. Yasuda K, Cho E, Nakajima M, Kawai K. Diagnosis of submucosal lesions of the upper gastrointestinal tract by endoscopic ultrasonography. Gastrointest Endosc. 1990;36:s17-20. 